\title{
INDONESIAN COURSE ONTOLOGY BASED ON SEMANTIC WEB
}

\author{
Rusdy Agustaf ${ }^{1}$ \\ ${ }^{1}$ Department of Informatics Engineering, Janabadra University, Indonesia
}

\begin{abstract}
Ontology's can be used to support a knowledge management system and opens the possibility to move from document-oriented view toward knowledge are interrelated, can be combined, and can be reused in a more flexible and dynamic. Problems are concerning how to provide content subjects with attention to course. This study modelling students to course content based on ontology.
\end{abstract}

\section{KEYWORDS}

Ontology, Semantic Web, Knowledge Management

\section{INTRODUCTION}

In explaining the basic concepts in a domain in this case is the subject matter content as well as defining relationships in use ontology's [2]. Ontology's can be used to support a knowledge management system and opens the possibility to move from document-oriented view toward knowledge are interrelated, can be combined, and can be reused in a more flexible and dynamic. Ontology is a way of representing knowledge of the meaning of objects, properties of an object, and the object relations that may occur on the domain knowledge $[5,7,25]$.

Course content is based on the context of the Broad Guidelines Principal Teaching (BGPT) in accordance with the curriculum used. Problems are concerning how to provide content subjects with attention to course. This study modelling students to course content based on ontology.

\section{LITERATURE REVIEW}

\subsection{Semantic Web}

The semantic web is idea Sir Tim Berners-Lee, inventor of the WWW, URIs, HTTP and HTML. Sir Tim Berners-Lee defines the Semantic Web as a development of the current web in which information has a well defined meaning (well defined meaning), better enabling computers and people to work together [23]. Web semantics, better known by the term web 3.0 is an efficient way to represent data on the World Wide Web, or as a database that is connected globally [23]. 


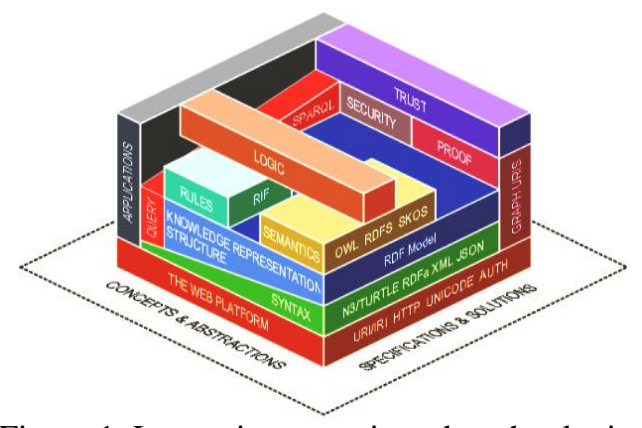

Figure 1. Layers in semantic web technologies

In the manufacture of the semantic web involves a set of standards which are coordinated by the World Wide Web Consortium (W3C). Standards in making the concept of the semantic web design is divided into several layers of technologies such as in Figure 1 [23], this technology consists of:

\section{- Web Platform includes Unicode and URI}

Unicode is a standard character representation computer. URI (Uniform Resource Identifier) is the standard for the location and identity of a resource (i.e. a web page).

- Syntax includes N3, N-Triple, Turtle (terse RDF Triple Language), RDFa, XML, and JSON

N3 (Notation 3), N-Triple, Turtle (terse RDF Triple Language) is a serialization syntax for $\mathrm{RDF}$ or RDF representation in the form of a triple. RDFa (Resource Description Framework in Attributes) as an additional attribute in XHTML based on RDF subject-predicate-object expressions. XML (Extensible Markup Language) and Namespace, is a syntax rules that serve to present the data on the structure of the web, but do not emphasize limits on the meaning of the document. XML Schema is a language for restricting the structure of XML and XML data type enriching. JSON (JavaScript Object Notation) is a simple form of textbased data exchange.

- Knowledge Representation Structure

An RDF (Resource Description Framework) a model for knowledge representation in a simple format that can be triple represented in graph form to explain the resources and relationships.

- Semantic

An advanced stage of knowledge representation by describing properties and classes of RDF resources contained in known as RDF Schema (RDFS) and the language ontology (Ontology vocabulary) recommended by W3C on February 10, 2004 known as the Web Ontology Language (OWL). OWL is a richer language (extension of RDF) and complex to describe the resource. OWL uses a triple format, the same as RDF.

- Rules

A Rule Interchange Format (RIF) which can be used to perform reasoning on the ontology so that it can be concluded whether a particular resource qualifies.

- Query Implemented using SPARQL. SPARQL is a query language for RDF.

- Security

Authentication protocol is implemented by SSL / TLS.

- Proof

This section determines the validity of a semantic web including interoperability and scalability. This section is shown with the possible occurrence of multiple RDF graphs.

- Trust

This section allows the user to trust a web semantic knowledge information. 


\section{- Application}

The top part of this layer is a form of utilization of the semantic web in the form of a web application.

\subsection{Ontology}

Ontology is a formal explicit specification of a conceptualization [13]. Conceptualization is an abstract picture of something in the world that wants to be represented. Ontology provides a shared vocabulary that can be used to model a domain, which is the type of an object, and / or concepts that exist, and property and their relationships [3]. Ontology's are used in artificial intelligence (artificial intelligence), the semantic web, software engineering, biomedical informatics, and on the science of informatics as a form of knowledge representation.

The basis of the design of the ontology consists of the following components:

1. Concept

Used in a broad understanding. A concept can be something that was said, so it can also be an explanation of the duties, functions, action, strategy, and so on. Concept also known as classes, objects and categories.

2. Relation

Represents a type of interaction between the concept of a domain. Formally can be defined as a subset of a product of $\mathrm{n}$ sets, $\mathrm{R}: \mathrm{C} 1 \mathrm{x} \mathrm{C} 2 \mathrm{X}$. , , x Cn. As an example of the relation binaries includes subclass-of and connected-to.

3. Function

Is a special relationship where the element of relationship is unique to the element to $n-1 . \mathrm{F}$ : $\mathrm{C} 1 \times \mathrm{C} 2 \mathrm{x} .,, \mathrm{Cn}-1$ i> Cn, for example, is Mother-of.

4. Axioms

Used to model a sentence which always correct.

5. Instances

Used to represent the individual elements.

Ontology together with a set of individual instances of classes establish a knowledge base. Some of the reasons why the need to create ontology is:

- To determine the general understanding of the structure of information among people or software agents

- To enable reuse of domain knowledge

- To make domain assumptions explicit

- To separate domain knowledge from the operational knowledge

- To analyze domain knowledge

With ontology, knowledge can be represented in a language that can be understood by machines (machine readable). Additionally ontology's enables communication between the software agent because of the element that is understandable semantics or meaning of these agents.

\subsection{RDF (Resource Description Framework)}

In the semantic web, referring to things that exist in the world as resources. Resource can be whatever someone wants to discuss. Rusdy, lecture, "the value of X", and "all teachers in Janabadra" are examples of things that a person may be discussed and may be a resource in the semantic web. Resource is an entity or object on a concept. Resource is the word used in the 
semantic web standards. RDF is the basis of semantic web technology that serves as a standard for describing resources [23].

At RDF, a fact or a statement that expressed wish to be represented in the form of a triple, where there is a subject, predicate, and object (Powers, 2003). Suppose there's the fact: "Rusdy man", then "Rusdy" is the subject, "a" is the predicate, and "man" is the object. These three words are the resources. "Rusdy" is a resource, "a" is a resource, and "man" is also a resource. This naming is global so that when for example there is the statement "Rusdy has a bag" (Figure 2.4), the computer will know that "Rusdy" on "Rusdy man" is equal to "Rusdy" on "Rusdy have bag". Therefore, to distinguish each resource used URI (Unified Resource Identifier). URI is a globally unique naming system and is a generalization of the URL so that it has a similar format to the URL on the website. Suppose the statement "has Rusdy bag" wants to be represented in the URI will look like this:

$$
\begin{aligned}
& \text { Rusdy } \rightarrow<\text { http://www.some.com/ujb007\#Rusdy }>\text {; } \\
& \text { has } \rightarrow<\text { http://www.some.com/ukm007\#has }>\text {; } \\
& \text { bag } \rightarrow<\text { http://www.some.com/ukm007\#bag>. }
\end{aligned}
$$

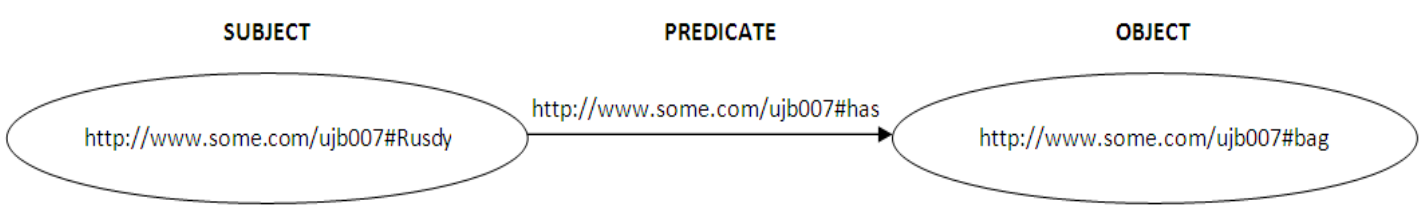

Figure 2. RDF graphs of data models "Rusdy has bag"

If you would like to represent the statement "Rusdy has bag" in the form of triple URI need to write:

<http://www.some.com/ujb007\#Rusdy http://www.some.com/ujb007\#has http://www.some.com/ujb007\#bag>.

\subsection{SPARQL}

RDF data model in the form of a statement in the form of a triplet consisting of a subject, predicate, and object. To get information from an RDF graph takes a query. SPARQL is a query language that can be used to access data on the semantic web [23]. By using SPARQL makes it possible to:

- Taking the value of the data is unstructured or semi-structured data.

- Develop data by querying a relation that is not known.

- Can perform complex queries join operation on different database more simply.

- RDF transforms the data into another vocabulary.

The results of SPARQL query can return values in some data formats such as: XML, JSON, RDF, and HTML. Here is a simple example of SPARQL:

Data :

<http://example.org/book/book1><http://purl.org/dc/elements/1.1/title> "SPARQL Tutorial".

Query :

SELECT ?title 


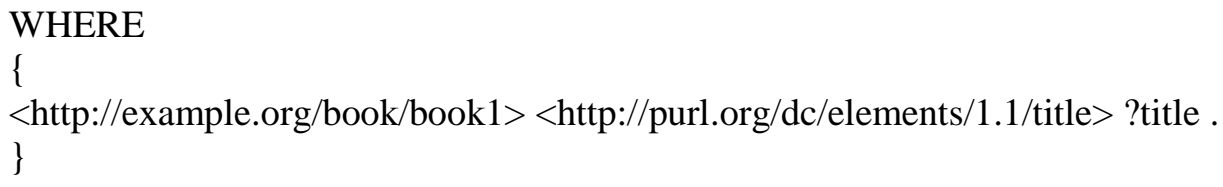

Result :

\begin{tabular}{|c|}
\hline title \\
\hline "SPARQL Tutorial" \\
\hline
\end{tabular}

SPARQL variables start with "?" And a node (resource or literal) in the RDF triple. While the statement "SELECT" returns a table of variables and values described in the query.

\section{Design Ontology Model}

In designing the ontology used tool protégé. Design class and hierarchy follow figure 3.

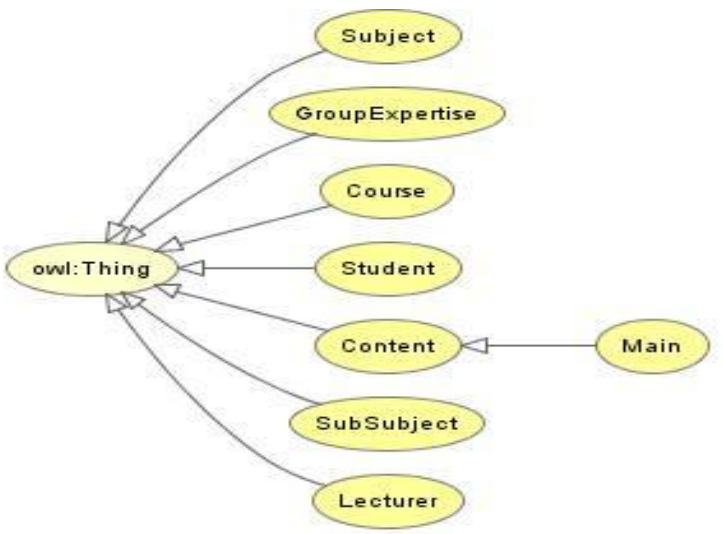

Figure 3. Class hierarchy

Here is an explanation for each of these classes:

a. Course

Is a class that represents the course to be taken by the Student and taught by Lecturer

b. GroupExperise

Is a class that represents a group of expertise for a Course.

c. Lecturer

Is a class that represents teachers (lecturers) are propping / teach a course.

d. Student

Is a class that represents students.

e. Subject

Is a class that represents the subject matter of the courses used in the learning process through e-Learning Course.

f. SubSubject

Is a class that represents a sub subject matter of the courses used in the learning process through e-Learning Course.

g. Content

Is a class that represents the learning resources used in the learning process through eLearning Course. 
International Journal of Web \& Semantic Technology (IJWesT) Vol.7, No.2, April 2016

Relations between classes arranged through the property. The design of the property following the figure 4 .

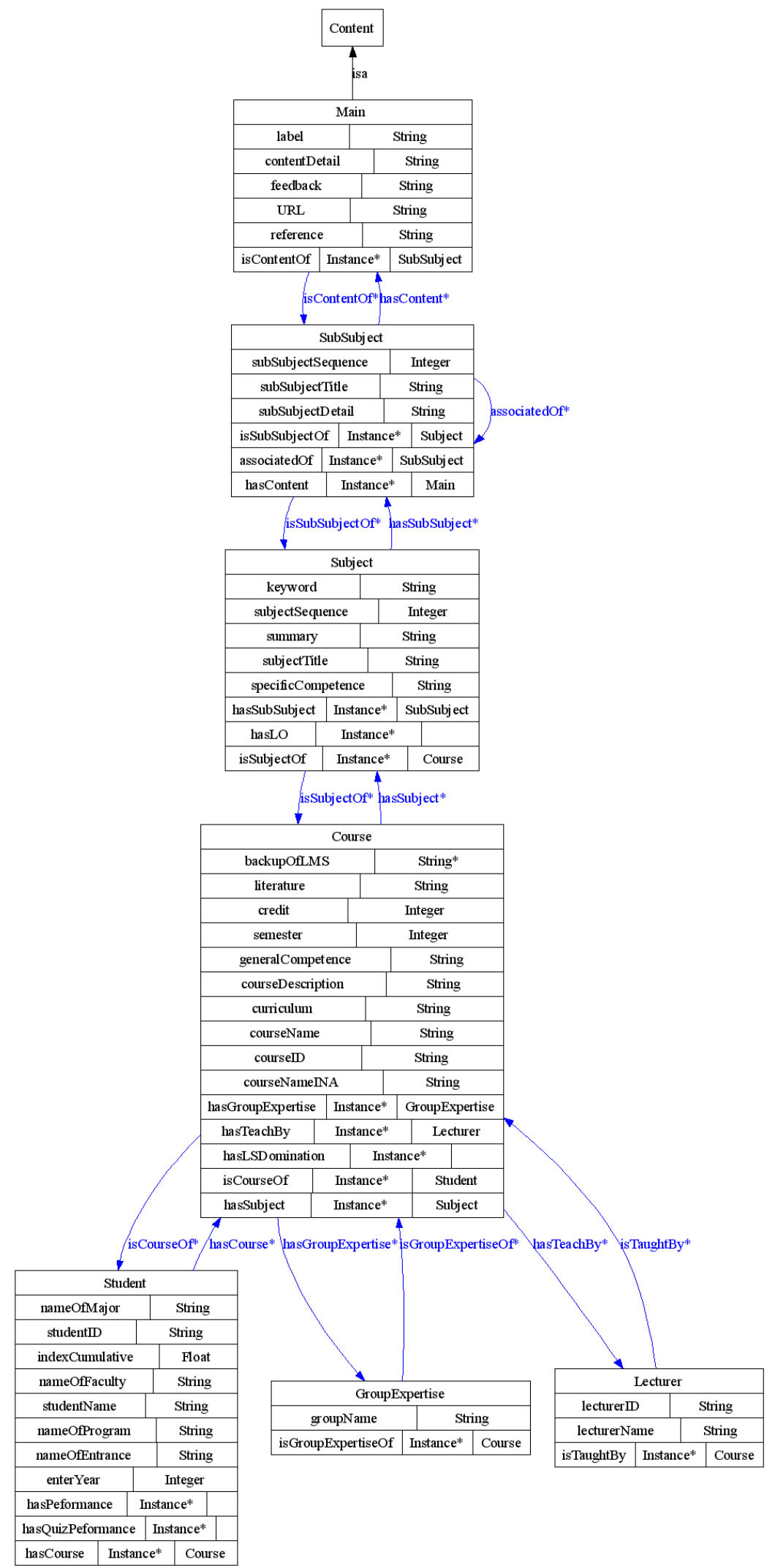

Figure 4. Course Property Class Diagram Relationships 
Step defining an instance of the class begins by selecting a class, make individual instance of the class went on to give the value of each property that has been defined as in Figure 5.

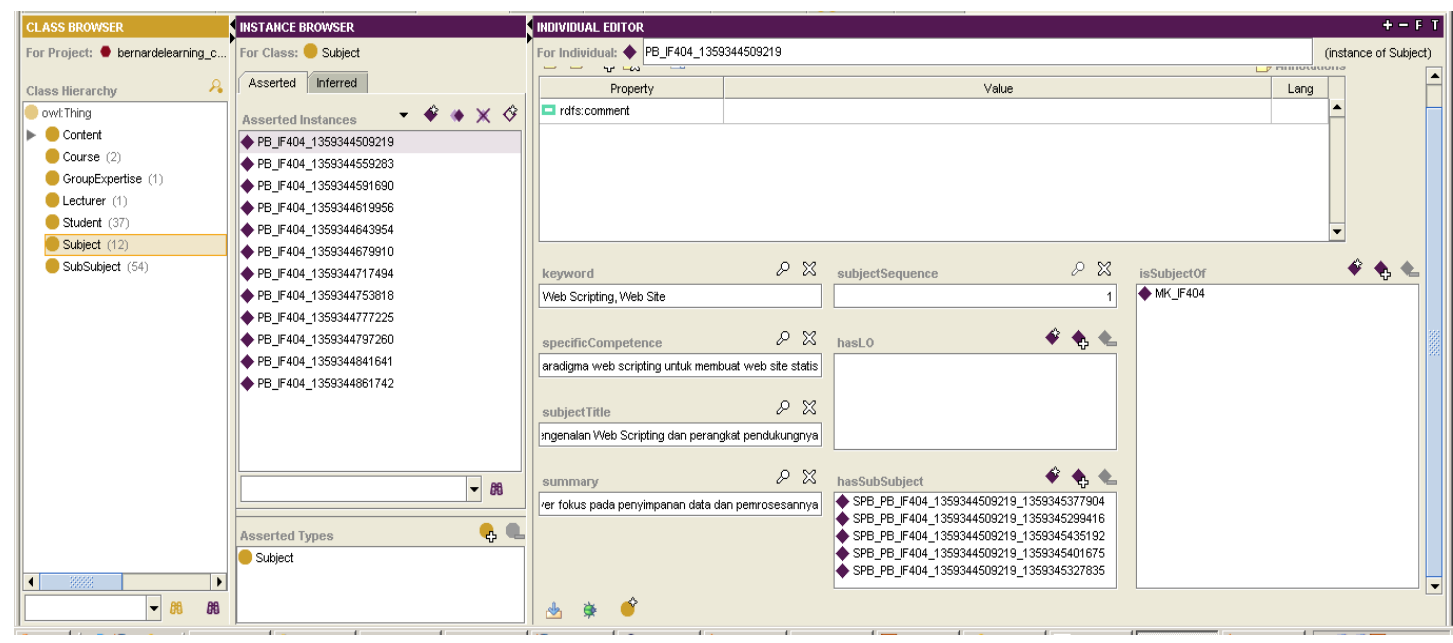

Figure 5. Defining the Class Instance

\section{RESUlts AND TESTING}

The final goal of this research is the result showed the content of the courses. The case studies used in the test was a course web programming with code IF404 in Information Engineering study program. Tests carried out using SPARQL.

\begin{tabular}{|c|c|c|c|}
\hline Query & 棈: & Results & \\
\hline \multirow{12}{*}{$\begin{array}{l}\text { SELECT ?Topic } \\
\text { WHERE \{ } \\
\text { ?a :isSubjectOf :MK_IF404. } \\
\text { ?d :hasSubject ?b. } \\
\text { ?b :subjectTitle ?Topic. } \\
\text { \} }\end{array}$} & & Topic & \\
\hline & & JSON & 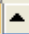 \\
\hline & & Javascript & 1 \\
\hline & & Pengelolaan tata letak content dengan perintah HTML lanjut dan pengiriman data & \\
\hline & & DHTML dengan Javascript & \\
\hline & & JQuery Framework & \\
\hline & & Perintah CSS untuk manipulasi tampilan content & \\
\hline & & Format content dengan Perintah HTML-XHTML dasar & \\
\hline & & AJAX & \\
\hline & & Hosting Web & \\
\hline & & Manipulasi XML dengan Javascript & \\
\hline & & XML & \\
\hline Execute Query & & Pengenalan Web Scripting dan perangkat pendukungnya & $\nabla$ \\
\hline
\end{tabular}

Figure 6. Topics Testing and Results for IF404

\section{CONCLUSiON}

Ontology model for content course case study web programming courses in Information Engineering study program has successfully created and tested. Ontology's are implemented to organize content according BGPT knowledge. 


\section{REFERENCES}

[1] Allemang, Dean, Hendler, dan James., 2010, Semantic Web for the Working Ontologist, Morgan Kauffman Publisher.

[2] Antonio, G., dan Harmelen, F.V.A, 2008, Semantic Web Primer (Cooperative Information Systems series), The MIT Press.

[3] Arvidsson, Fredrik, Flycht-Eriksson, dan Annika, 2002, Ontologies I, http://www.ida.liu.se/ janma/SemWeb/Slides/ontologies1.pdf, diakses 7 Juli 2012.

[4] Carver, C.A., Howard, R.A., dan Lane, W.D., 1999, Enhancing student learning through hypermedia courseware and incorporation of student learning styles, IEEE Transactions on Education, 42 (1), 33 38.

[5] Chandrasekaran, B. dan Josehson, J., 1999 What are Ontologies, and Why Do We Need Them?, IEEE Intelligent Systems, vol 14(1), hal. 20-26.

[6] Cristani, M. dan Cuel, R., 2005, A Survey on Ontology Creation Methodologies. International Journal on Semantic Web and Information Systems, vol 1(2).

[7] Eberhart, A., 2004, Ontology-based Infrastructure for Intelligent Applications, Disertasi Doktor, der Naturwissenschaftlich-Technischen Fakultat der Universitat des Saarlandes, Saarbrucken.

[8] Felder, R.M., dan Spurlin, J., 2005, Applications, reliability and validity of the Index of Learning Styles, International Journal on Engineering Education, vol 21(1), 103-112.

[9] Felder, R.M., dan Silverman, L. K., 1988, Learning and Teaching Styles in Engineering Education, Engineering Education Journal, vol 78 no 7, 674-681.

[10] Felder, R.M., dan Soloman, B. A., 1997, Index of Learning Styles Questionnaire, http://www.engr.ncsu.edu/learningstyles/ilsweb.html, diakses 30 November 2007.

[11] Felder, R.M., 2002, Learning And Teaching Styles In Engineering Education, http://www4.ncsu.edu/unity/lockers/users/f/felder/public/Papers/LS-1988.pdf, diakses 27 Juni 2012.

[12] Franzoni, A. L., dan Assar, S., 2009, Student Learning Styles Adaptation Method Based on Teaching Strategies and Electronic Media, Journal Educational Technology \& Society, vol 12, 15-29.

[13] Gruber, T.,1993, A translation approach to portable ontology specifications, Knowledge Acquisition, http://tomgruber.org/writing/ontolinguakaj-1993.pdf, diakses 7 Juli 2011.

[14] Hong, H., dan Kinshuk, 2004, Adaptation to student learning styles in web based educational systems, Proceedings of World Conference on Educational Multimedia, Hypermedia \& Telecommunications (ED-MEDIA), pp 491-496.

[15] Jonassen, D. H., dan Grabowski, B. L., 2003, Handbook of Individual Differences, Learning, and Instruction, Lawrence Erlbaum Associates, Hillsdale, New Jersey.

[16] Junqi, W., Zhengbing, H., Zongkai, Y., dan Yumei, L., 2009, Effective Learning Activities Design with LAMS, International Conference on Networks Security, Wireless Communications and Trusted Computing.

[17] Kuljis, J., dan Liu, F., 2005, A Comparison of Learning Style Theories on the Suitability for Elearning, Proceedings of the Iasted Conference on Web Technologies, Applications, and Services, ACTA Press, 191-197.

[18] Litzinger, T.A., Lee, S.H., Wise, J.C., dan Felder, R.M., 2005, A study of the reliability and validity of the Felder-Soloman Index of Learning Styles, Proceedings of the ASEE Annual Conference, American Society for Engineering Education.

[19] Ng, P., Pinto, J., dan Williams S.K., 2011, The Effect of Learning Styles on Course Performance: A Quantile Regression Analysis, Academy of Educational Leadership Journal, vol 15 (1), 15-38.

[20] Noy, N. F. dan McGuinness, D. L., 2001, Ontology development 101: A guide to creating your first ontology, Technical Report KSL-01-05, Stanford Knowledge Systems Laboratory.

[21] Paredes, P., dan Rodríguez, P., 2004, A Mixed Approach to Modelling Learning Styles in Adaptive Educational Hypermedia, Advanced Technology for Learning Journal, vol 1 no 4, 210-215.

[22] Patrick S., Kennedy K., dan Powell A., 2013, Mean What You Say: Defining and Integrating Personalized, Blended and Competency Education, iNACOL, The International Association for K12 Online Learning Press.

[23] Suteja, B.Renaldy, 2015. Model Personalisasi e-Learning berbasis Gaya Belajar Felder Silrverman dengan Pendekatan Pola Perilaku yang Relevan. Disertasi, Universitas Gadjah Mada.

[24] Suteja, B. Renaldy., Guritno S, Wardoyo R, Ashari A, 2010. Personalized Online Learning with Ontological Approach, International Journal Computer Science Issue, vol 7. 
International Journal of Web \& Semantic Technology (IJWesT) Vol.7, No.2, April 2016

[25] Tamma, V.A.M., 2002. An Ontology Model Supporting Multiple Ontologies for Knowledge Sharing. PhD Thesis, University of Liverpool.

[26] Velazquez, A.L.F., dan Assar, S. 2007, Using learning styles to enhance an e-learning system, http://www.public.int-evry.fr/ assar/pdf/ECEL07_Franzoni.pdf, diakses 20 maret 2014.

[27] Xie, X., Hua-Jun, Zeng., dan Wei-Ying, Ma., 2002, Enabling Personalization Services on the Edge, Microsoft Research Asia.

[28] Yao, H, Orme, A.M. dan Etzkorn, 1., 2005, Cohesion Metrics for Ontology Design and Application, Journal of Computer Science, vol 1(1), hal.107-113.

[29] Zywno, M.S., 2003. A contribution to validation of score meaning for Felder-Soloman's Index of Learning Styles, Proceedings of the ASEE Annual Conference. American Society for Engineering Education. 